\title{
Visual evoked potentials in Negro carriers of the gene for tyrosinase positive oculocutaneous albinism
}

\author{
DAVID CASTLE*, JENNIFER KROMBERG*, RENEE KOWALSKY*, \\ ROOKSHANA MOOSA*, NATALIE GILLMAN*, ESTHER ZWANE*, \\ AND VIVIAN FRITZ† \\ From * the MRC Human Ecogenetics Research Unit, Department of Human Genetics, School of Pathology, \\ South African Institute for Medical Research and University of the Witwatersrand; and †Department of \\ Neurology, Johannesburg Hospital, Johannesburg, South Africa.
}

SUMMARY Visual evoked potential testing was performed on 15 Negro carriers of the gene for tyrosinase positive oculocutaneous albinism in order to detect whether they have the same visual pathway decussation anomalies as do homozygotes. No subject showed $01-02$ asymmetry on monocular testing, indicating that decussation follows the normal pattern. It is concluded that visual evoked potential testing is probably not useful in the detection of Negroes heterozygous for the gene for tyrosinase positive oculocutaneous albinism.

Oculocutaneous albinism is an autosomal recessive congenital hypomelanosis involving the skin, hair, and eyes. It has a prevalence of 1:3900 in South African Negroes, ${ }^{1}$ among whom the tyrosinase positive form is the most common.

Abnormalities of visual pathway decussation have been well documented in albino animals as well as humans. $^{2}{ }^{3}$ In homozygotes for the albinism gene, an abnormal proportion of fibres from the ganglion cells of the temporal retina decussate to the contralateral cerebral hemisphere. This decussation anomaly can be definitively detected by demonstration of monocular visual evoked potential asymmetry. ${ }^{4}$

As Negro carriers of the gene for tyrosinase positive albinism had not been previously assessed to determine whether they might also have some degree of visual pathway decussation anomaly, we undertook visual evoked potential testing in such a group. Our aim was to assess the use of such testing in detecting heterozygotes.

\section{Materials and methods}

The test group comprised 15 Negro women who were obligate heterozygotes for the tyrosinase positive albinism allele, each having at least one tyrosinase positive albino offspring. Only females were selected to avoid problems of non-paternity. The age range was 18 to 61 years $($ mean $=35 \cdot 7)$. All

Received for publication 3 December 1987.

Revised version accepted for publication 22 February 1988. subjects were healthy, specifically having no history of central nervous system dysfunction or of visual disturbance other than refractive errors. All subjects underwent testing of visual acuity (Snellen chart) and colour perception (Ishihara charts). They were examined for strabismus and nystagmus and for iris translucency. Direct fundoscopy was also performed.

Visual evoked potential testing was based on the methods of Apkarian et al, ${ }^{4}$ for detection of decussation anomalies. The visual stimulus was a two per second alternating black and white checkerboard pattern presented on a television screen $1 \mathrm{~m}$ from the subject being tested. Five electrodes were applied to the scalp: one $10 \%$ above the nasion (FPZ); a row of three over the occipital cortex, one in the midline $(0 \mathrm{Z})$ and one each at $10 \%$ to the left (01) and right (02) of the midline; and an earth electrode was applied to the vertex (CZ). Each patient was tested binocularly and then monocularly for each eye, and all tracings were duplicated for verification. Potentials were averaged on a Cadwell 7400 and recorded on XY graph paper and the $01-02$ difference potential for the binocular and each monocular set of visual evoked potentials was computed for each subject.

The 01-02 difference potential of the principal component between 75 and $125 \mathrm{msec}$ indicates the percentage of fibres from retinal ganglion cells reaching the striate cortex of each hemisphere (right and left). ${ }^{4}$ Normally there would be little discrepancy between the 01-02 difference potential recorded monocularly for each eye, because of the symmetry 


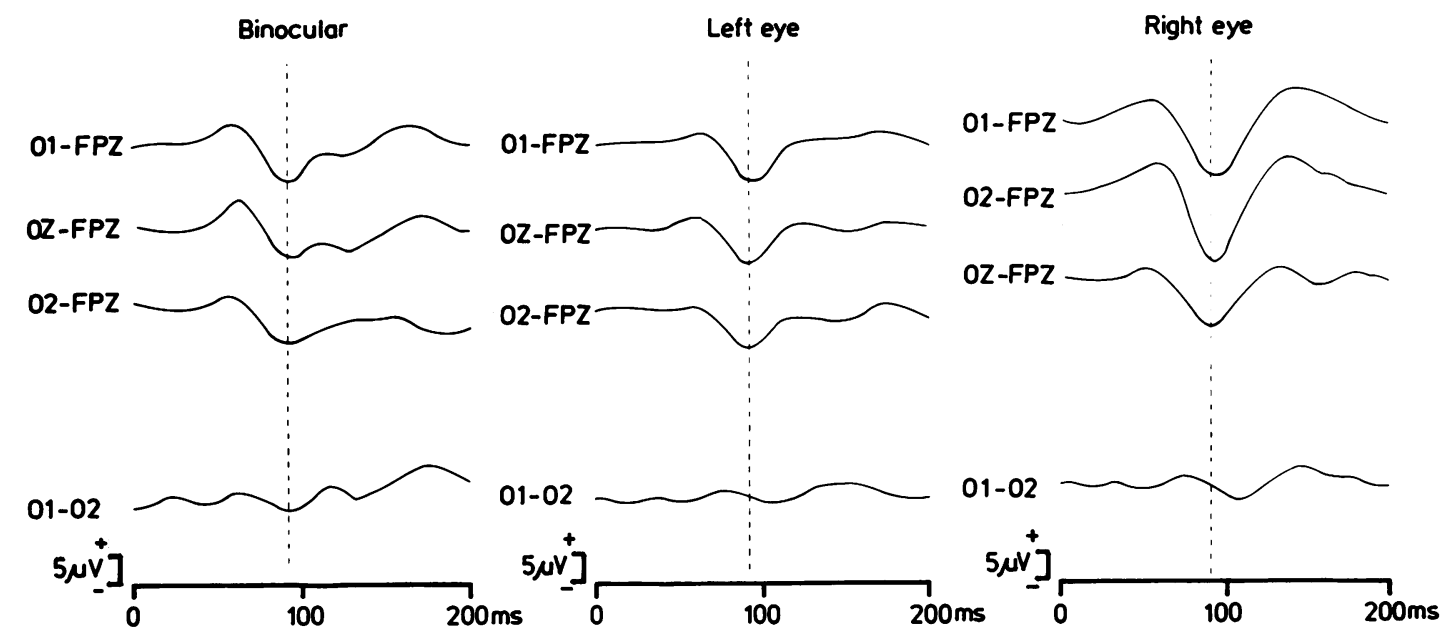

FIGURE A visual evoked potential tracing from a carrier of the gene for tyrosinase positive oculocutaneous albinism. Note the symmetry of the 01-FPZ and 02-FPZ tracings in the monocular recordings, and the lack of inversion of the 01-02 difference potential tracing between recordings for the left and right eye.

in optic decussation in normal subjects (in whom about $55 \%$ of fibres decussate). In albino subjects, over $80 \%$ of the fibres decussate, and this results in a marked asymmetry in the $01-02$ difference potential on monocular stimulation for each eye. ${ }^{5} 6$

\section{Results}

Subjects had no visual abnormalities other than refractive errors, which were corrected with glasses. None had strabismus or nystagmus or abnormalities of colour perception. All had brown irides, and no iris translucency could be detected. Fundoscopy showed normal retinal pigment (three patients had negroid stippling) and no evidence of foveal hypoplasia.

An example of a visual evoked potential recording from one subject is given in the figure. There is a slight asymmetry in the recording for each hemisphere on binocular stimulation; this is a normal physiological variation and is not significantly exacerbated on monocular stimulation. The 01-02 difference potential of the principal component between 75 and $125 \mathrm{msec}$ shows no discrepancy between the left and right monocular recordings, suggesting that no abnormality in visual pathway decussation exists in this subject. The tracings for all 15 subjects were similarly within normal limits.

\section{Discussion}

The ability to detect heterozygotes for any recessive condition opens the way to definitive genetic coun- selling and may also enhance understanding of the condition itself. Heterozygote detection for recessive albinism has not been widely addressed, but one promising finding was that Negro carriers of the tyrosinase positive gene have significantly lighte skin than their peers homozygous for the normat allele. ${ }^{7}$ Froggatt ${ }^{8}$ considered that his finding of an increased incidence of iris translucency in heterozygotes reflected a relative paucity of ocular pigment in these subjects.

Creel et al $^{9}$ have shown that subjects with $\mathrm{X}$ linked and autosomal recessive ocular albinism, where the eyes alone are hypopigmented, show visual pathway decussation anomalies identical to those in oculocutaneous albinos. These findings have led to the hypothesis that the decussation anomalies in albinos are a direct result of lack of pigment in the developing visual tract. However, Leventhal et $a l^{10}$ showed that normally pigmented cats heterozygous for a c locus tyrosinase negative albinism allele themselves exhibited the decussation anomalies found in hypopigmented cats homozygous for this allele. Their conclusion was that either $N$ the visual pathway anomalies in albinos are not the result of hypopigmentation itself but rather of an as $N$ yet unknown (pleiotropic) effect of the albinism $\underset{\mathrm{N}}{N}$ gene, or that heterozygotes do, in fact, have $\underset{\sigma}{\sigma}$ significantly reduced visual pathway melanin, result- 0 ing in a developmental misrouting of fibres.

The more recent finding that hypopigmented $\stackrel{\mathcal{D}}{?}$ Prader-Willi patients have visual pathway anomalies 0 identical to those in albinos ${ }^{11}$ would seem to indicate $\bar{O}$ that lack of pigment is itself the cause of the 
misrouting of fibres. However, it may be that those Prader-Willi patients with hypopigmentation have a deletion of part of the albinism locus, suggesting that this locus is on chromosome 15 (15q11.2q13). Even though there is no strict correlation between hypopigmentation, abnormal visual evoked potentials, and a microscopic deletion of the long arm of chromosome 15 in Prader-Willi patients, ${ }^{11}$ a significant correlation may be found using molecular DNA techniques looking for a specific deletion of 15q.

That we failed to detect decussation anomalies in our pigmented heterozygote subjects seems to support the hypothesis of a direct correlation between ocular hypopigmentation and developmental visual pathway anomalies. We cannot comment on any pigment 'dose effect' (as found in animals by Guillery $^{2}$ ) in that even though Negroes heterozygous for the albinism gene have significantly lighter skin than normal controls, ${ }^{7}$ we have not been able to show that this has any parallel effect on neuronal development. Visual evoked potential testing, such as used in this study, may be insufficiently sensitive to detect decussation anomalies involving less than the $20^{\circ}$ of temporal fibres which decussate in homozygote albinos, and the use of techniques like half field stimulation may be required.

In conclusion, we have shown that optic pathway misrouting does not seem to occur in Negro carriers of the gene for tyrosinase positive oculocutaneous albinism. Visual evoked potential testing is probably not a useful test for detection of carriers of the gene for this type of albinism.

We wish to thank Professors Peter Bartel and Trefor Jenkins for their advice and useful criticism. The medical superintendent of the Johannesburg Hospital allowed the use of facilities. DC acknowledges the support of an MRC Research Scholarship. Janet Robbie typed the manuscript.

\section{References}

1 Kromberg JGR, Jenkins T. Prevalence of albinism in the S A Negro. S Afr Med J 1982;61:383-6.

2 Guillery RW. Visual pathways in albinos. Sci Am 1974;230: 44-54.

${ }^{3}$ Creel D, Witkop CJ, King RA. Asymmetric visually evoked potentials in human albinos: evidence for visual system anomalies. J Invest Ophthalmol 1974;13:430-40.

4 Apkarian P, Reits D, Spekreijse H, van Dorp D. A decisive electrophysiological test for human albinism. Electroencephalogr Clin Neurophysiol 1983;55:513-31.

${ }^{5}$ Kuroiwa Y, Celesia GG, Tohgi H. Amplitude difference between pattern evoked potentials after left and right hemifield stimulation in normal subjects. Neurology (Minneap) 1987;37: 795-9.

6 Creel D, Spekreijse H, Reits D. Evoked potentials in albinos: efficacy of pattern stimuli in detecting misrouted optic fibres. Electroencephalogr Clin Neurophysiol 1981;52:595-603.

${ }^{7}$ Roberts DF, Kromberg JGR, Jenkins T. Differentiation of heterozygotes in recessive albinism. J Med Genet 1986;23:323-7.

${ }^{8}$ Froggatt P. Albinism in Northern Ireland. Ann Hum Genet 1960;24:213-32.

9 Creel D, O'Donnell FE, Witkop CJ. Visual system anomalies in human ocular albinos. Science 1978;201:931-3.

${ }^{10}$ Leventhal AG, Vitek DJ, Creel DJ. Abnormal visual pathways in normally pigmented cats that are heterozygous for albinism. Science 1985;229:1395-7.

11 Creel DJ, Bendel CM, Wiesner GL, Wirtschafter JD, Arthur DC, King RA. Abnormalities of the central visual pathways in Prader-Willi syndrome associated with hypopigmentation. N Engl J Med 1986;314:1606-9.

Correspondence and requests for reprints to Dr J G R Kromberg, Department of Human Genetics, South African Institute for Medical Research, PO Box 1038, Johannesburg 2000, South Africa. 